\title{
Laparoscopic Sleeve Gastrectomy, with or without Staple Line Reinforcement
}

\author{
Subhi A. Shihan ${ }^{1}$, Issam Salih AL-Janabi ${ }^{2}$ \\ ${ }^{1}$ General Surgery Specialist, Ramadi Teaching Hospital, Baghdad-Iraq, \\ ${ }^{2}$ Consultant Surgeon, Baghdad Teaching Hospital Medical City, Baghdad-Iraq
}

\begin{abstract}
Background: Overweight and obesity are defined as abnormal or excessive fat accumulation that presents a risk to health. A crude population measure of obesity is the body mass index. The surgical treatment of morbid obesity is termed bariatric surgery, Laparoscopic sleeve gastrectomy first described by Gagner. Specific complications have been reported, including staple-line bleeding and staple-line leaks, Staple line reinforcement is extensively debated and highly recommended by most surgeons in an attempt to reduce postoperative complication.
\end{abstract}

Aim of the Study: To compare the early complication of sleeve gastrectomy with or without staple line reinforcement by over-sewing.

Patients and Method: Prospective study from $1^{\text {st }}$ January 2013 to $31^{\text {st }}$ January 2015, four or five ports used according to surgeon preference but all of them used graduated cartridge size, some of them used to reinforce the staple line by Prolin or Vicryl and others did not. The patient was follow up for one month after surgery by direct contact with the surgical team.

Conclusion: there was no statistically difference in the incidence of leak or bleeding in cases of sleeve gastrectomy with or without staple-line reinforcement by over sewing.

Keyword: Laparoscopic sleeve gastrectomy; Leak; Bleeding; staple line reinforcement.

\section{Introduction}

Overweight and obesity are defined as abnormal or excessive fat accumulation that presents a risk to health. A crude population measure of obesity is the body mass index (BMI), a person's weight (in kilograms) divided by the square of his or her height (in meters). A person with a BMI of 30 or more is generally considered obese. A person with a BMI equal to or more than 25 is considered overweight ${ }^{(1)}$.

The overweight and obesity are major risk factors for a number of chronic diseases, including diabetes, cardiovascular diseases and cancer. Once considered a problem only in high income countries, overweight and obesity are now dramatically on the rise in lowand middle-income countries, particularly in urban settings ${ }^{(2)}$.

The surgical treatment of morbid obesity is termed bariatric surgery. It had its origin in the 1950s, when mal-absorptive operation were first performed for sever hyperlipidemia syndromes (jejuno-ileal bypass), this operation, however produced unacceptable metabolic complication ${ }^{(3)}$.

Table 1: The World Health Organization classification of obesity by body mass index as

\begin{tabular}{|l|c|}
\hline Classification & BM $\left(\mathbf{K g} / \mathbf{m}^{\mathbf{2}}\right)$ \\
\hline Normal range & $18.5-24.9$ \\
\hline Pre-obese & $25.0-29.9$ \\
\hline Obese class I & $30.0-34.9$ \\
\hline Obese class II & $35.0-39.9$ \\
\hline Obese class III & $=>40$ \\
\hline
\end{tabular}

Laparoscopic sleeve gastrectomy (LSG), first described by Gagner ${ }^{(4)}$ in 2003 , has become a well standardized therapeutic option for the surgical treatment 
of different degrees of obesity ${ }^{(5)}$. Since its introduction, LSG has gained acceptance due to its technical simplicity and the convincing outcomes (6). While specific complications have been reported, including staple-line bleeding and staple-line leaks are the most serious as they are associated with the greatest morbidity. The incidence of this type of leak after LSG varies in different series ${ }^{(4)}$ and its management has been attempted using several different therapeutic approaches ${ }^{(7)}$.

Gastric leaks can be due to mechanical or ischemic causes. According to Baker etal ${ }^{(8)}$ a leak caused by stapler misfiring, usually appear within 2 day of surgery, compared to the "ischemic causes" that usually appear on day 5-6 post operatively and can be caused by improper vascularization due to an aggressive dissection especially of the posterior attachments of the upper sleeve, thermal injuries to the gastric tube by ultrasonic devices (harmonic), and Ligature can cause a leak which seen after the first week post-operative ${ }^{(9)}$.

A leak can be proximal at the gastro esophageal junction or distally at the lower end of the sleeve $\mathrm{e}^{(10)}$.

Patients with distal stenosis are more likely to have proximal leaks, because of gastric emptying impairment leading to increased intraluminal pressure and decreased compliance of the gastric tube ${ }^{(11)}$.

Staple line reinforcement (SLR) is extensively debated and highly recommended by most surgeons in an attempt to reduce postoperative complication $(12,13,14,15)$ staple line reinforcement (SLR) is not well standardized and involves different options; over-sewing of the staple line ${ }^{(16)}$ application of buttressing biological material ${ }^{(17)}$.

To date, many studies have investigated the safety and efficacy of SLR. The results of these studies however remain inconsistent rather than conclusive ${ }^{(18)}$.

Since the subject has some debate, we plan to compare the early complication of sleeve gastrectomy with or without staple line reinforcement by oversewing.

\section{Patients and Method}

Prospective study, conducted in Baghdad Teaching Hospital and Dijlah Private Hospital for the period from 1st January 2013 to 31st January 2015.
Patients with morbid obesity whom subjected to sleeve gastrectomy by different surgeon, four or five ports used according to surgeon preference but all of them used graduated cartridge size, the larger one used in the antrum of the stomach and the smaller size cartridge for the body and fundus. Some of them used to re-inforce the staple line by Prolin or Vicryl no. (2.0) and others did not. All of them used bougie size $36 \mathrm{Fr}$.

Patient who are smoker or diabetic or hypertensive were excluded, since diabetes mellitus and hypertension may interfere with wound healing and bleeding profile.

The patient was followed up for one month after surgery by direct contact with the surgical team. The early complication was recorded namely: the leak and bleeding. Patients with postoperative bleeding some of them manifested early as blood discharge via the drain and other presented later as hematoma demonstrated by imaging study.

Regarding postoperative leak most of them presented after one week with tachycardia, vomiting, tachypnea, shoulder pain and elevated WBC count. the presence of leak demonstrated by C.T scan with oral contrast. (one Patient with hematoma turned to be a leak were considered as a leak in this study). The non-surgical complication (such as respiratory and cardiovascular, etc...) were excluded. The factors that may affect the rate of complications such as: age, gender, BMI and the reinforcement of stapler line also recorded.

The data were analyzed using the available software packages of Statistical Packages for Social SciencesVersion 22 (SPSS-22) and presented in simple measures of frequency, percentage, and range (minimummaximum).

Chi-square test was used to calculate the significance of difference between proportions. $\mathrm{P}$ value of equal or less than 0.05 was considered as the level of statistical significance.

\section{Results}

During the three years of the study, 120 patients were included, 33 male and 87 female (male to female ratio $1: 2.6$ ). The ages of patients ranged from 18 to 50 years, $30.8 \%$ of the patients were older than 40 years (table 2). 
Table 2: The age and gender distribution of the studied sample

\begin{tabular}{|c|c|c|c|c|}
\hline \multirow{7}{*}{$\begin{array}{l}\text { Age } \\
\text { (Years) }\end{array}$} & Age Group & No & \multicolumn{2}{|r|}{$\%$} \\
\hline & $<20$ & 7 & \multicolumn{2}{|r|}{5.8} \\
\hline & 20---24 & 19 & \multicolumn{2}{|c|}{15.8} \\
\hline & 25---29 & 21 & \multicolumn{2}{|c|}{17.5} \\
\hline & $30---34$ & 21 & \multicolumn{2}{|c|}{17.5} \\
\hline & $35---39$ & 15 & \multicolumn{2}{|c|}{12.5} \\
\hline & $\geq 40$ & 37 & \multicolumn{2}{|c|}{30.8} \\
\hline \multirow{3}{*}{ Gender } & Gender & No & $\%$ & \multirow{3}{*}{$\begin{array}{c}\text { Male : Female } \\
1: 2.6\end{array}$} \\
\hline & Male & 33 & 27.5 & \\
\hline & Female & 87 & 72.5 & \\
\hline
\end{tabular}

The BMI of our patients ranged from 40 to $63 \mathrm{KG} /$ $\mathrm{m} 2$, most of them (74 patients) with BMI less than 50 $\mathrm{KG} / \mathrm{m}^{2}$ (table 3).
Table 3: The BMI distribution of the studied sample

\begin{tabular}{|l|l|c|c|}
\hline \multirow{4}{*}{ BMI $\left(\mathrm{Kg} / \mathrm{m}^{2}\right)$} & BMI group & No & \% \\
\cline { 2 - 4 } & $40---44.9$ & 32 & 26.7 \\
\cline { 2 - 4 } & $45---49.9$ & 42 & 35 \\
\cline { 2 - 4 } & $50---54.9$ & 28 & 23.3 \\
\cline { 2 - 4 } & $=>55$ & 18 & 15 \\
\cline { 2 - 4 } & Total & $\mathbf{1 2 0}$ & $\mathbf{1 0 0}$ \\
\hline
\end{tabular}

Regarding the complication rate, three patients out of 57 patients whom their gastric sleeve stapler line was reinforced by over sewing developed a leak proved by contrast study. While in patients without reinforcement, a leak was documented in two patients out of 63 there was no statistical significance difference between the two (table no 3). Regarding the bleeding rate one patient out of 57 patients with SLR and two patients out of 63 patients without SLR, there was no statistical significance difference between the two groups (table 4).

Table 4: The complications (leakage or bleeding) distribution of the studied sample by type of operation

\begin{tabular}{|c|c|c|c|c|c|c|}
\hline & & \multicolumn{4}{|c|}{ Total no of patients $=120$} & \multirow{3}{*}{ P value } \\
\hline & & \multicolumn{2}{|c|}{ With reinforcement (57 patients) } & \multicolumn{2}{|c|}{ Without (63 patients) } & \\
\hline & & No & $\%$ & No & $\%$ & \\
\hline \multirow{2}{*}{ Leakage } & Yes & 3 & 5.3 & 2 & 3.2 & 0.567 \\
\hline & No & 54 & 94.7 & 61 & 96.8 & \\
\hline \multirow{2}{*}{ Bleeding } & Yes & 1 & 1.8 & 2 & 3.2 & 0.619 \\
\hline & No & 56 & 98.2 & 61 & 96.8 & \\
\hline
\end{tabular}

*Significant difference between proportions using Pearson Chi-square test at 0.05 level.

In attempt to further analyze the difference in complication rates between the subgroups of age, gender and BMI, the complications distributed according to these subgroups as shown in table 5 and table 6 .

Regarding the leak in relation to age groups, we found leak in three patients with reinforcement all of them were above 40 years old, other two patients without reinforcement who were younger in age as shown in table
5 , but because of the small number of complication, no statistical test could be applied in this subgroup.

Regarding the relation between the bleeding and the BMI of the patients, we found bleeding in two patients with BMI more than $55 \mathrm{KG} / \mathrm{m}^{2}$ and one bleeding with BMI less than $55 \mathrm{KG} / \mathrm{m}^{2}$ (table 6) but because of the small number of complication, no statistical test could be applied in this subgroup. 
Table 5: The leakage complication distribution of the studied sample by type of operation according to difference variables

\begin{tabular}{|c|c|c|c|c|c|}
\hline & & \multicolumn{4}{|c|}{ Operation type } \\
\hline & & \multicolumn{2}{|c|}{ With reinforcement } & \multicolumn{2}{|c|}{ Without } \\
\hline & & Leakage & No & Leakage & No \\
\hline \multirow{6}{*}{ Age (Years) } & $<20$ & - & 4 & - & 3 \\
\hline & $20---24$ & - & 10 & - & 9 \\
\hline & $25---29$ & - & 8 & 1 & 12 \\
\hline & $30---34$ & - & 8 & 1 & 12 \\
\hline & $35---39$ & - & 8 & - & 7 \\
\hline & $=>40$ & 3 & 16 & - & 18 \\
\hline \multirow{2}{*}{ Gender } & Male & 1 & 17 & 2 & 13 \\
\hline & Female & 2 & 37 & - & 48 \\
\hline \multirow{4}{*}{ BMI (Kg/m2) } & 40---44.9 & - & 12 & 1 & 19 \\
\hline & $45---49.9$ & 1 & 23 & 1 & 17 \\
\hline & $50---54.9$ & 1 & 14 & - & 13 \\
\hline & $=>55$ & 1 & 5 & - & 12 \\
\hline
\end{tabular}

Table 6: The bleeding complication distribution of the studied sample by type of operation according to difference variables

\begin{tabular}{|c|c|c|c|c|c|}
\hline & & \multicolumn{4}{|c|}{ Operation type } \\
\hline & & \multicolumn{2}{|c|}{ With reinforcement } & \multicolumn{2}{|c|}{ Without } \\
\hline & & Bleeding & No & Bleeding & No \\
\hline \multirow{6}{*}{ Age (Years) } & $<20$ & - & 4 & - & 3 \\
\hline & $20---24$ & - & 10 & - & 9 \\
\hline & $25---29$ & - & 8 & 1 & 12 \\
\hline & $30---34$ & - & 8 & - & 13 \\
\hline & $35---39$ & 1 & 7 & - & 7 \\
\hline & $=>40$ & - & 19 & 1 & 17 \\
\hline \multirow{2}{*}{ Gender } & Male & 1 & 17 & 1 & 14 \\
\hline & Female & - & 39 & 1 & 47 \\
\hline \multirow{4}{*}{$\mathrm{BMI}\left(\mathrm{Kg} / \mathrm{m}^{2}\right)$} & 40----44.9 & - & 12 & - & 20 \\
\hline & $45---49.9$ & - & 24 & - & 18 \\
\hline & $50---54.9$ & - & 15 & 1 & 12 \\
\hline & $\Rightarrow>55$ & 1 & 5 & 1 & 11 \\
\hline
\end{tabular}

\section{Discussion}

Laparoscopic sleeve gastrectomy is increasingly applied as a promising stand-alone operation in bariatric surgery for its satisfactory effect on weight loss and decreased operative risk ${ }^{(19,20)}$. The most common and severe complications following LSG are staple line 
leak and bleeding that all surgeons want to avoid ${ }^{(20,21)}$. Staple line reinforcement is strongly advocated to prevent these adverse events, although there's no highgrade evidence in the literature for its need during $\mathrm{LSG}^{(22,23,24)}$. According to the survey on LSG at the Fourth international consensus summit on Sleeve gastrectomy, 75\% surgeons chooses to perform SLR ${ }^{(25)}$. Among them, $57 \%$ of them use buttressing materials and $43 \%$ oversew the staple line.

In this study which included 120 patients (57 patients with SLR and 63 patients without) are compared to other studies, Stefano D'Ugo et al(26), Italy 1162 patients (973 patients with SLR and 189 patients without), Jean knapps et al(27), USA 4830 patients (3342 patients with reinforcement and 1488 patients without), Gill RS et al ${ }^{(28)}$,Canada 116 patients all of them with SLR and Kasalicky $\mathrm{M}$ et al ${ }^{(29)}$, Czech 61 patients all of them without SLR.

This study was conducted in two hospital involving four surgeons but Stefano D’Ugo et al and Jean Knapps et al studies were multicenter studies, while Gill et al and Kasalicky et al studies were isolated individually each of them in one center .

Regarding the age, the mean age in this study was more than 40 years that is comparable to Stefano D'Ugo et al (mean age $=43.7$ years) and Gill Rs et al (mean age $=44$ years) studies.

Regarding to the male to female ratio, in this study the ratio was $(1: 2.6)$ that is nearly comparable to the studies of Stefano D'Ugo et al (1:2.5) and Jean Knapps et al (1:3) and Kasalicky $M$ et al (1:2.3) this reflect the fact that obesity are more common in female and the female are more interested about their body shape .

Regarding to BMI, in this study the majority of BMI (35\%) was $45-49,9 \mathrm{~kg} / \mathrm{m} 2$, that is comparable to Stefano D'Ugo et al (mean BMI $=48 \mathrm{~kg} / \mathrm{m} 2$ ) and Gill Rs et al (mean BMI $=44.7 \mathrm{~kg} / \mathrm{m}^{2}$ ).

Regarding the percentage of sleeve gastrectomy with or without SLR, in this study was $47.5 \%$ with SLR and $52.5 \%$ without, that's different from other studies in which the percentage of sleeve gastrectomy with SLR more than without as in the study of Stefano D'Ugo et al (83.5\% with SLR and $16.5 \%$ without) and the study of Jean Knapps et al (69\% with SLR and 31\% without).
Regarding to leak rate, in this study the leak was identified in three cases out of 57 patients with SLR $(5.3 \%)$ and two cases out of 63 patients without (3.2\%), while in the study of Stefano D'Ugo et al the overall rate of leak was $2.8 \%$ with SLR and $4.8 \%$ without, that's versus result of this study in related to percentage but both of them statistically non significant among the difference between staple line with or without reinforcement, in the study of Jean Knapps et al the leak rate was 3.9\% in SLR and $3.2 \%$ without reinforcement which comparable to this study, while in the study of Gill Rs et al there was no leak out of 116 patients all of them with SLR also in the study of Kasalicky M et al there was no leak out of 61 cases all of them without SLR, in all study above there are no statistically difference in both technique of gastric sleeve about the leak complication.

Regarding the post operative bleeding in this study one case out of 57 cases with SLR had bleeding (1.8\%), while two cases out of 63 cases without SLR developed bleeding (3.2\%) in compare to Stefano D'Ugo et al study the bleeding rate was $3 \%$, with a higher frequency being observed without SLR which comparable to this study, while in the Gill Rs et al study bleeding occurred just in one case $(0.9 \%)$ out of 116 cases all of them with SLR and his conclusive that SLR in sleeve gastrectomy limits postoperative bleeding in contrast to Kasalicky $M$ et al study which show no case of bleeding out of 61 cases all of them without SLR, conclusively no significant difference between two technique.

We triad in this study to further evaluating the effect of Age and BMI on complication rate as shown in table $(5,6)$ but Due to small no of complication in the subgroups there was no statistical method applicable to compare between them.

\section{Conclusion}

There was no statistically difference in the incidence of leak or bleeding in cases of laparoscopic sleeve gastrectomy with or without staple - line reinforcement by over sewing.

Declarations: Conflict of Interest the authors declare that there are no potential conflicts of interest related to the study.

\section{Source of Funding: Nil}

Ethical Clearance: This research has exemption as it a routine treatment (no new materials were used). 


\section{References}

1. WHO. Obesity and overweight Fact sheet $\mathrm{N}^{\circ} 311$. January 2015. Retrieved 2 February 2016

2. World Health organization, obesity and overweit, WHO, 2015 (updated January 2015). Available from: www.WHO/topics/obesity/en .

3. Richards WO. Morbid Obesity. In: Sabiston Textbook of Surgery: The biological basis of modern surgical practice. Beauchamp RD, Evers M, Mattox KL \& Townsend CM, Eds. $19^{\text {th }}$ ed. Chapter 15, Elsevier \& Saunders International Edition. 2014, PP: 338.

4. Gagner M \& Rogula T. Laparoscopic re-operative sleeve gastrectomy for poor weight loss after biliopancreatic diversion with duodenal switch. ObesSurg, 2003; 13(4):649-45.

5. Tucker ON, Szomstein S \& Rosenthal RJ. Indications for sleeve gastrectomy as a primary procedure for weight loss in the morbidly obese. $\mathrm{J}$ GastrointestSurg, 2008; 12(4):662-67.

6. Roa PE, Kaidar-Person O, Pinto D, Cho M, Szomstein S \& Rosenthal RJ. Laparoscopic sleeve gastrectomy as treatment for morbid obesity: Technique and short-term outcome. ObesSurg, 2006; 16(10):1323-26.

7. de Aretxabala X, Leon J, Wiedmaier G, Turu I, Ovalle C, Maluenda F, Gonzalez C, Humphrey J, Hurtado M \& Benavides C. Gastric leak after sleeve gastrectomy: Analysis of its management. ObesSurg, 2011; 21(8):1232-39.

8. Aker RS, Foote JP, Brady R, Vroegop T \& Serveld $\mathrm{M}$. The science of stapling and leaks.ObesSurg, 2004;14:1290-98. (PubMed).

9. Sakran N, Goitein D, Raziel A, Keidar A, Beglaibter N, Grinbaum R, Matter I, Alfici R, Mahajna A, Waksman I, etal. Gastric leaks after sleeve gastrectomy: A multicenter experience with 2834 patients. SurgEndosc, 2013;27:240-45. (PubMed).

10. Choi SH \& Kasuma K. How to manage complications. Bariatric \& Metabolic Surgery, 2014; 2(21);108-15.

11. Yehoshua RT, Eidelman LA, Stein M, Fichman S, Mazor A, Chen J, Bernstine H, Singer P, Dickman $\mathrm{R}$, Beglaibter $\mathrm{N}$, etal. Laparoscopic sleeve gastrectomy: Volume and pressure assessment. ObesSurg, 2008;18: 1083-88. (PubMed)

12. Chen B, Kiriakopoulos A, Tsakayannis D, etal.
Reinforcement does not necessarily reduce the rate of staple line leaks after sleeve gastrectomy. A review of the literature and clinical experiences. ObesSurg, 2009; 19(2): 166- 72.

13. Kasalicky M, Michalsky D, Housova J, etal. Laproscopic sleeve gastrectomy without an oversewing of the staple line. ObesSurg, 2008; 18(10): 1257-62.

14. Albanopoulos K, Tsamis D, Arapaki A,etal. Staple line reinforcement with stitch in laparoscopic sleeve gastrectomy. Is it useful or harmful? J LaproendoscAdvSurg Tech, 2015; 25(7): 581-85.

15. Bulbuller N, Aslaner A, Oner OZ, etal. Comparison of four different methods in staple line reinforcement during laparoscopic sleeve gastrectomy. Inter J ClinExpMed, 2013; 6(10):985-90.

16. Musella M, Milone M, Maietta P, etal. Laparoscopic sleeve gastrectomy,efficacy of fibrib sealant in reducing postoperative bleeding. A randomized controlled trial.Update Surg, 2014; 66(3): 197-201.

17. Shah SS, Todkar JS \& Shah PS.Buttressing the staple line; a randomized comparison between stale- line reinforcement versus no reinforcement during sleeve gastrectomy.ObesSurg, 2014; 24(12): 2014-20.

18. RaafaYahiaAfifi, MD (Professor). Peer review report 2 on "The efficacy of staple line reinforcement during laparoscopic sleeve gastrectomy: A metaanalysis randomized controlled trials".http:// www.journal- surgery.net/home. January-June, 2016Volume 25, Supplement 1, Page 44.

19. A,M, Carlin, T,M, Zeni, W.J. English, et al, The comparative effectiveness of sleeve gastrectomy, gastric bypass, and adjustable gastric banding procedures for treatment of morbid obesity, Ann. Surg.257(5) (2013) 791- 797.

20. R.S, Kruger. V.E, pricolo, T,T Streeter, et al, A bariatric surgery center of excellence; operative trends and long-term outcomes,J, Am, Coll, Surg, 218(6) (2014) 1163-1174.

21. H. Buchwald, Y, Avidor, E. Braunwald, et al, Bariatric surgery; a systematic review and metaanalysis, JAMA 292(14) (2004)1724-1737.

22. B. Chen. A, Kiriakopoulos, D. Tsakayannis, et al, Reinforcement does not necessarily reduce the rate of staple-line leaks after sleeve gastrectomy . A review of the literature and clinical experiences, Obes, Surg. 19(2) (2009)166-172. 
23. Gentileschi, P. Camperchioli, I. DUgo, S. et al. staple-line reinforcement during laparoscopic sleeve gastrectomy using three different techniques; a randomized trial, Surg. Endosc. 26(9) (2012) 2623-2629.

24. Consten, E.C. Gagner, M. staple-line reinforcement techniques with different buttressing materials used for laparoscopic gastrointestinal surgery; a new strategy to diminish perioperative complications, Surg. Technol. Int. 13(2004)59-63.

25. M. Gagner, M, Deitel, A,I, Erickson, et al, survey on laparoscopic sleeve gastrectomy (LSG) at the Fourth International Consensus summit on sleeve gastrectomy, Obes. Surg.23(12) (2013) 2013-2017.
26. Stefano D’Ugo, M.D., Department of Experimental Medicine and Surgery, Tor Vergata University, Viale Oxford 81, 00133 Rome, Italy

27. Department of Surgery, Central Michigan University College of Medicine, 1000 Houghton Avenue, 2nd Floor Saginaw, MI 48602, USA.

28. Department of Surgery, University of Alberta, Edmonton, Alberta, Canada.

29. First Surgical Department, Fist Medical Faculty, Charles University of Prague, Nemocnice 2128 08, Prague 2, Czech Republic. kasalicky@atlas.cz. 